\title{
PERSPECTIVAS DO ENSINO DE HISTÓRIA: ATIVIDADES EXTENSIONISTAS NO ENSINO FUNDAMENTAL EM IGUATU-CE
}

\author{
Joilson Silva de Souza \\ UECE \\ joilson.sousa@uece.br \\ Roseane Fernandes Feitosa \\ UECE \\ roseanefernandes03@gmail.com \\ Laís Maria Pereira Costa \\ UECE \\ lais.costa@aluno.uece.br
}

\begin{abstract}
Resumo
Este artigo apresenta os dados iniciais das atividades do projeto de extensão: Ensino de História e Consciência Histórica: apoio pedagógico aos alunos do Santo Antônio em Iguatu-Ce, aprovado pela Pró-Reitoria de Extensão da Universidade Estadual do Ceará - UECE, para ser desenvolvido no ano de 2018 na linha de Extensão: Metodologias e estratégias de ensino/aprendizagem, que ocorre na Faculdade de Educação, Ciências e Letras de Iguatu - FECLI. O referido projeto, objetiva potencializar a consciência histórica dos alunos do ensino fundamental em Iguatu-Ceará, a partir da prática docente dos estudantes de pedagogia e os alunos da comunidade de Santo Antônio, priorizando a formação de um cidadão consciente dos seus direitos e deveres, do seu lugar histórico e estabelecendo uma ligação com o local onde habitam. Destarte, o fundamento teórico-metodológico utilizado se alinha ao ensino de história, consciência histórica e aprendizagem histórica fundamentado em autores como Fernando Cerri, Selva Guimarães, Itamar Freitas e Jörn Rüsen. O método crítico de abordagem pretende construir um senso de criticidade e simultaneamente procurar integrá-los na estrutura social e cultural em que estão inseridos, através de atividades didáticas aos discentes envolvidos utilizando de maneira interdisciplinar ao ensino de história. Percebe-se dificuldades de letramento com alunos de $4^{\circ}$ e $5^{\circ}$ ano do ensino fundamental. Contudo, no que concerne ao lugar social onde se está inserido e o reconhecimento deste como ponto de pertence, pode-se acreditar que o projeto em desenvolvimento estabelece relações de construção entre alunos e bolsistas de significações e sentidos.
\end{abstract}

Palavras-chave: Ensino de História. Lugar social. Consciência histórica.

\section{HISTORY TEACHING PERSPECTIVES: EXTENSION ACTIVITIES IN ELEMENTARY EDUCATION IN IGUATU-CE}

\begin{abstract}
This article presents the initial data of the extension project activities: Teaching History and Historical Consciousness: pedagogical support to the students of Santo Antônio in Iguatu-Ce, approved by the Pro- Rectory of Extension of the State University of Ceará - UECE, to be developed in the year 2018 in the line Extension: Methodologies and teaching / learning strategies, which takes place in the Faculty of Education, Sciences and Literature of Iguatu - FECLI. This project aims to strengthen the historical awareness of students of elementary education in IguatuCeará, based on the teaching practice of students of pedagogy and students of the community of Santo Antônio, prioritizing the formation of a citizen aware of their rights and duties, of their historical place and establishing a connection with the place where they live. Thus, the theoretical-methodological foundation used is aligned with the teaching of history, historical
\end{abstract}


consciousness and historical learning based on authors such as Fernando Cerri, Selva Guimarães, Itamar Freitas and Jörn Rüsen. The critical approach method seeks to build a sense of criticality and simultaneously seek to integrate them into the social and cultural structure in which they are inserted, through didactic activities to the students involved using interdisciplinary teaching of history. Literacy difficulties can be seen with $4^{\circ}$ and $5^{\circ}$ grade students. However, with regard to the social place where one is inserted and the recognition of this as a point of belonging, one can believe that the project in development establishes relations of construction between students and scholars of significations and senses.

Keywords: Teaching History. Social place. Historical consciousness.

\title{
PERSPECTIVAS DE LA ENSEÑANZA DE HISTORIA: ACTIVIDADES EXTENSIONISTAS EN LA ENSEÑANZA FUNDAMENTAL EN IGUATU-CE
}

\begin{abstract}
Resumen
Este artículo presenta los datos iniciales de las actividades del proyecto de extensión: Enseñanza de Historia y Conciencia Histórica: apoyo pedagógico a los alumnos de Santo Antônio en Iguatu-Ce, aprobado por la Pro-Rectoría de Extensión de la Universidad Estatal de Ceará - UECE, para ser desarrollado en el año 2018 en la línea de Extensión: Metodologías y estrategias de enseñanza / aprendizaje, que ocurre en la Facultad de Educación, Ciencias y Letras de Iguatu - FECLI. Este proyecto, objetiva potenciar la conciencia histórica de los alumnos de la enseñanza fundamental en Iguatu-Ceará, a partir de la práctica docente de los estudiantes de pedagogía y los alumnos de la comunidad de Santo Antônio, priorizando la formación de un ciudadano consciente de sus derechos y deberes, de su lugar histórico y estableciendo una conexión con el lugar donde habitan. De este modo, el fundamento teórico- metodológico utilizado se alinea a la enseñanza de la historia, la conciencia histórica y el aprendizaje histórico fundamentado en autores como Fernando Cerri, Selva Guimarães, Itamar Freitas y Jörn Rüsen. El método crítico de abordaje pretende construir un sentido de criticidad y simultáneamente tratar de integrarlos en la estructura social y cultural en que están insertados a través de actividades didácticas a los discentes involucrados utilizando de manera interdisciplinaria a la enseñanza de la historia. Se percibe dificultades de letra con alumnos de $4^{\circ}$ y $5^{\circ}$ año de la enseñanza fundamental. Sin embargo, en lo que concierne al lugar social donde se inserta y el reconocimiento de éste como punto de pertenencia, se puede creer que el proyecto en desarrollo establece relaciones de construcción entre alumnos y becarios de significaciones ysentidos.
\end{abstract}

Palabras clave: Enseñanza de Historia. Lugar social. Conciencia histórica. 


\section{INTRODUÇÃO}

A legislação brasileira fundamenta o tripé composto pelo ensino, pela pesquisa e pela extensão, estabelecendo o eixo estrutural da Universidade brasileira, garantindo ainda que este não pode ser compartimentado (MOITA; ANDRADE, 2009, p.269). Segundo aponta a Constituição Brasileira de 1988, no artigo 207 sobre o papel das universidades, entende-se que estas “[...] obedecerão ao princípio da indissociabilidade entre ensino, pesquisa e extensão”. Portanto, as funções básicas das instituições de nível superior devem dar igual tratamento às mesmas para não violarem os elementos prescritivos legalísticos.

Este artigo, de abordagem qualitativa corrobora com as diretrizes referentes à universidade, alinhado sobretudo a extensão universitária, através da promoção de interação dos docentes e discentes universitários com as comunidades situadas em seu entorno, especificamente a comunidade do Santo Antônio, em Iguatu-Ceará, onde se localiza a Faculdade de Educação, Ciências e Letras de Iguatu FECLI.

O projeto de extensão supra intitulado "Ensino de História e Consciência Histórica no ensino fundamental I: apoio pedagógico aos alunos do Santo Antônio em Iguatu-Ce", propõe a inserção de estudantes do curso de pedagogia em uma atividade direcionada para o benefício dos alunos através de ações educativas popularmente denominada pelos pais dos mesmos de "reforço escolar comunitário". Esta interação entre as duas partes (universidade e comunidade), acontece a partir de uma demanda historicamente situada das camadas menos favorecidas no ambiente universitário como espaço de atendimento interdisciplinar. $\mathrm{O}$ desenvolvimento de atividades metodológicas de ensino é relevante para a formação, considerando que esta proposta apresenta beneficiar tanto à comunidade, quanto aos discentes acadêmicos, implicando no fato destes serem de um curso de licenciatura onde a prática de ensino e docência é pertinente durante o progresso de suas habilidades como educadores.

Os questionamentos norteadores que fundamentam nossa ação extensionistas e que nos colocam em posição de refletirmos sobre nosso papel formal e social do ensino, são: Que história ensinar na escola de educação básica dentro da conjuntura de um mundo globalizado e multicultural em que estamos inseridos? Quais os significados a história têm atualmente em meio a uma geração marcada pelos valores da tecnologia do século XXI? Desse modo, recorremos ao historiador inglês Eric Hobsbawm (1995), onde apresenta que a destruição do passado é um dos fenômenos mais lúgubres do final do nosso século XX, apontando que “[...] quase todos os jovens crescem numa espécie de 
presente contínuo, sem qualquer relação orgânica com o passado público da época em que vivem.” (HOBSBAWM, 1995, p. 13).

Conforme a perspectiva historiográfica do intelectual britânico, observamos que dentro da conjuntura do século XX, o historiador ${ }^{1}$ assume papel importante dentro da sociedade, pois corrobora com a assertiva de relembrar à sociedade elementos importantes que constituem toda uma conjuntura e não somente o tempo presente. Portanto, buscamos a proximidade da academia com a comunidade onde a Faculdade de Educação Ciências e Letras de Iguatu - FECLI/UECE está inserida.

Esta pesquisa, acontece tanto nas dependências da Escola de Ensino Fundamental Else Lima Verde Montenegro, que fica próxima à universidade, pode potencializar uma relação didática de ensino e aprendizagem do ensino de história tanto para os alunos do curso de pedagogia, quanto para as crianças de $4^{\circ}$ e 5 ano do ensino fundamental, que terão a oportunidade de vivenciar práticas docentes promovidas pelos estudantes de licenciatura em pedagogia não apenas no espaço escolar em seu contra turno, mas utilizando ainda, os laboratórios que o curso de pedagogia dispõe como por exemplo, os laboratórios de informática, brinquedoteca e materiais didáticos que a universidade dispõe e pode promover ações formativas de aprofundamento docente

\section{FUNDAMENTOS TEÓRICOS}

O ensino de história tem espaço reservado no currículo do ensino fundamental, pois a interação entre o conhecimento e a prática social se apresentam em um movimento contínuo de construção e reconstrução com suas semelhanças e contradições (GUIMARÃES, 2012, p. 61). Deste modo, é pertinente afirmar que consideramos o conhecimento histórico produzido em sala de aula como relações socialmente vivas, situadas dentro de um determinado tempo e considerando que nos anos iniciais do ensino fundamental, a problematização do estudo histórico inicia-se sempre pela leitura local, que se torna objeto de análise constante (BITTENCOURT, 2011, p.114).

Passamos a relacionar o papel da história ao ofício do historiador em saber como é produzida, escrita e mediada para as várias gerações. Guimarães (2012), nos lembra que o fazer histórico tem diferentes formas em como o conhecimento histórico é

\footnotetext{
${ }^{1}$ Denominamos este profissional aquele que ministra a disciplina de história em toda a educação básica, incluindo neste caso, os professores que se debruçam pelo ensino de história nas séries iniciais do ensino fundamental.
} 
e chega até nós. Ao citar o historiador inglês Edward Palmer Thompson (1981 apud GUIMARÃES, 2012, p.41-42), a autora sintetiza que “[...] é por meio dos diversos registros das ações humanas, dos documentos, dos monumentos, dos depoimentos de pessoas, de fotografias, objetos, vestuários e outros, que chega até nós o real vivido por homens e mulheres nos diversos tempos e espaços". Assim, todos os registros de fatos da ação do homem são considerados fontes de estudo da História.

Acerca do ensino de história mediado pelo professor na sala de aula, corroboramos com o pensamento de Schmidt e Cainelli (2009, p. 34), onde nos dizem que a prática docente deve buscar estar distante da imagem do professor-enciclopédia, detentor do saber, e estar procurando a constituição de um professor-consultor, que contribui para a construção do conhecimento de seus alunos em sala de aula. Nessa direção, o professor ajuda o aluno a pensar historicamente. É nesse sentido que se percebe a relevância que o educador tem quando apresenta ao educando a diversidade de fontes históricas a fim de potencializar sua autonomia e criticidade. Lecionar a disciplina de história passa a ser um meio de o aluno se sentir parte do processo de construção do fazer histórico na sala de aula, pois a este lugar "[...] não é apenas o espaço onde se transmite informações, mas o espaço onde se estabelece uma relação em que interlocutores constroem significações e sentidos." (SCHMIDT e CAINELLI, 2009, p. 35).

Para Guimarães (2012, p. 80), a História, constitui um campo de saber fundamental na luta pela construção de uma sociedade democrática e multicultural, o que se alinha com os aspectos prescritivos dos Parâmetros Curriculares Nacionais do componente curricular - História, quando aponta o desenvolvimento da capacidade de valorizar o direito de cidadania dos indivíduos, dos grupos e dos povos como condição de fortalecimento da democracia, mantendo-se o respeito às diferenças e a luta contra as desigualdades (GUIMARÃES, 2012, p.144).

Como professor, o papel de promover ao educando o que chamamos de "consciência história" alinhada ao ensino desta, encontra relação com os apontamentos do professor e pesquisador Fernando Cerri (2011), onde salienta que a rejeição de alunos em estudar história pode não ser apenas pela falta de compromisso discente com os estudos ou uma falta de destreza com a matéria, mas um confronto de ideias muito distintas sobre o tempo, que não fazem relação alguma com o tempo histórico vivido (CERRI, 2011). 
Para o também professor e pesquisador Itamar Freitas (2010), que corrobora com as ideias do pesquisador alemão Jörn Rüsen, entende-se que:

[...] aprender história é pensar e aprender a pensar historicamente, buscando constituir a consciência histórica, [...], ou seja, desenvolver as capacidades de rememorar experiências interpretá-las sob a forma de uma história e utilizá-las para um propósito prático em sua vida (FREITAS, 2010, p. 175).

Podemos dizer que aprender História não é apenas conhecer os fatos ocorridos, suas datas, entre outros fatos, mas sim, apropriar-se das experiências históricas, aprender a diferenciar as mesmas no tempo e espaço, conhecendo e ampliando esse conhecimento de base interpretativa e finalmente fazer relações com as experiências vividas no tempo presente, potencializando momentos de reflexão, orientação e se posicionando em seu cotidiano.

Segundo Freitas (2010, p. 176), Rüsen não investigou a aprendizagem histórica em crianças, mas elaborou uma hipótese que tem orientado algumas pesquisas. É possível que haja um expressivo encadeamento entre a idade dos alunos, as formas narrativas (conteúdos/modos de aprender/modos de interpretar) e o nível de educação alcançado. Assim, é provável que se possa identificar uma espécie de progressão das narrativas que o mesmo identifica entre os tipos tradicionais, exemplar, crítico e genética, sendo esta última, o tipo ideal para a vida contemporânea, pois está relacionada à formação de uma consciência histórica alinhada aos ideais democráticos e de humanização.

A educação como força motriz para o processo de emancipação do indivíduo é fator chave para a formação acadêmica dos educandos envolvidos no processo de ensino e aprendizagem direcionada com a mesma relevância para o ensino de história, pois, a partir desse estudo poderemos enfatizar o meio social que cada educando ocupa e sua verdadeira função na sociedade em que vive. Dessa maneira buscamos contribuir com a formação cidadã de estudantes dos anos iniciais do ensino fundamental a fim de potencializar sua identidade e cidadania através de uma aprendizagem escolar da história, pois como apontam os Parâmetros Curriculares Nacionais (BRASIL, 1997), para os anos iniciais do ensino fundamental direcionado a história, onde os mesmos estão voltados inicialmente para atividades em que os alunos possam compreender semelhanças, diferenças, permanências e transformações no modo de vida social, cultural e econômico inicialmente de sua localidade no decorrer do tempo, utilizando fontes históricas para este fim.

Acreditamos que com isso, alinhamos ainda a nova Base Nacional Comum 
Curricular em seus dispositivos que contemplam as competências direcionadas ao $4^{\circ}$ e $5^{\circ}$ ano quando nos diz que:

\footnotetext{
No $3^{\circ}$ e $4^{\circ}$ ano contemplam-se a noção de lugar em que se vive e as dinâmicas em torno da cidade, com ênfase nas diferenciações entre a vida privada e a vida pública, a urbana e a rural. Nesse momento, também são analisados processos mais longínquos na escala temporal, como a circulação dos primeiros grupos humanos. Essa análise se amplia no $5^{\circ}$ ano, cuja ênfase está em pensar a diversidade dos povos e culturas e suas formas de organização. A noção de cidadania, com direitos e deveres, e o reconhecimento da diversidade das sociedades pressupõem uma educação que estimule o convívio e o respeito entre os povos (BRASIL, 2017, p. 354. Grifos nosso).
}

Acreditamos que podemos potencializar uma articulação entre currículos para o $4^{\circ}$ e $5^{\circ}$ ano, enriquecendo metodologicamente, com uma diversidade de fontes históricas e métodos de ensino à formação de estudantes das séries iniciais do ensino fundamental e ainda, os estudantes acadêmicos que vivenciam na prática, o processo de ensino e difusão do conhecimento para com a sociedade. Com este propósito, objetivamos contribuir para a construção da consciência histórica dos alunos do Ensino Fundamental em Iguatu-Ceará e similarmente de uma cultura de prática docente entre os estudantes do curso de Pedagogia, possibilitando a interação entre academia e a sociedade priorizando a formação de um cidadão consciente dos seus direitos e deveres, do seu lugar histórico e estabelecendo uma ligação com o local onde habitam.

\section{METODOLOGIA}

Os conceitos teóricos-metodológicos a serem utilizados para a consolidação desse projeto de extensão pretende ser diversificado. O método crítico de abordagem que será aplicado para os alunos pretende construir um senso de criticidade e simultaneamente procurar integrá-los na estrutura social e cultural em que estão inseridos. Vale lembrar que segundo Minayo (2015, p.14) metodologia é "[...] o caminho do pensamento e a prática exercida na abordagem da realidade”.

O projeto tem como lócus de desenvolvimento a Escola de Ensino Fundamental Else Lima Verde Montenegro, onde ressaltando que é a única escola a qual possui turmas das séries iniciais do ensino fundamental $\left(4^{\circ}\right.$ e $5^{\circ}$ anos) onde foram estabelecidos diálogo e autorização por parte da gestão da escola, e responsáveis legais pelos alunos em reunião na referida escola em prol da criação de turmas para o reforço escolar.

O projeto de reforço escolar comunitário, funcionará no contra turno dos 
estudantes e será sediado inicialmente, nas próprias salas da instituição escolar disponibilizadas pelo núcleo gestor da escola onde foi confirmado acontecer nas quartasfeiras no turno da tarde para os alunos e alunas do quarto ano e as sextas-feiras no mesmo horário, para os quintos anos do ensino fundamental. Vale lembrar, que os recursos e materiais didáticos utilizados nas aulas de reforço são instrumentos produzidos pelos próprios discentes do curso de Pedagogia com o auxílio do professor coordenador do projeto. O apoio pedagógico aos alunos do Santo Antônio em Iguatu- Ceará, atende um público total de cerca de 24 (vinte e quatro) alunos, sendo 14 (quatorze) discentes do $4^{\circ}$ ano do ensino fundamental e 10 discentes do $5^{\circ}$ ano.

Foi utilizado como parâmetro para escolha dos alunos que compõem o reforço escolar, os resultados cedidos pela própria escola através do mapeamento do teste diagnóstico anual, realizado no início do ano letivo. De modo qualitativo e quantitativo participam do projeto os alunos com maior dificuldade na aprendizagem, obtidos através de dados coletados.

O projeto supracitado, tem seu pleno desenvolvimento utilizando elementos pertencentes ao ensino de História e a didática de maneira interdisciplinar, objetivando suprir as maiores dificuldades que a escola relata estar passando com esses discentes, atendendo dessa maneira as necessidades básicas dos alunos e aplicando o objetivo principal do projeto que é priorizar a construção de um cidadão consciente dos seus direitos e deveres, do seu lugar na história e estabelecer uma ligação entre o local onde habitam como prescreve os PCN do componente curricular de História para as séries iniciais do ensino fundamental.

\section{PRIMEIRAS ATIVIDADES}

Neste tópico, apresentam-se os dados iniciais obtidos conforme constam no diário de campo das bolsistas acadêmicas do curso de pedagogia, para mostrar o caminho percorrido até o presente momento no trabalho extensivo. A entrada em campo acontece de maneira bastante pontual. Nesta etapa, denominada de pesquisa exploratória, buscamos informes sobre uma escola possível de realização do trabalho extensivo e entrega de documentos com os agentes responsáveis. Registramos cada uma dessas etapas em computador com auxílio de um programa de processador de texto. Como apontam Bogdan e Biklen (1994), chamamos tais registros de "notas de campo", pois são: “o relato escrito daquilo que o investigador ouve, vê, experiencia e pensa no decurso da recolha e refletindo sobre os dados de um estudo qualitativo" (BOGDAN e BIKLEN, 1994, p. 150). 
O primeiro contato estabelecido para o desenvolvimento do projeto foi à visita efetuada à Secretaria Municipal de Educação da cidade de Iguatu - Ceará no dia 01 de março de 2018, em busca de informações das escolas localizadas no bairro Santo Antônio na cidade de Iguatu-Ceará e a forma de contatá-las para o desenvolvimento do presente projeto. O colaborador da instituição supra, informou que não seria necessária a autorização do órgão executivo do poder municipal, pois a coordenação e direção das escolas têm autonomia para efetivar qualquer tipo de atividade complementar que favoreça o desenvolvimento educacional de ensino e aprendizagem dos discentes em formação e que no bairro Santo Antônio em Iguatu-CE, existe apenas uma escola de ensino fundamental, nesse caso, a Escola de Ensino Fundamental Else Lima Verde Montenegro, situada na Rua Dário Rabelo, s/n bairro Santo Antônio na cidade de Iguatu-Ceará.

$\mathrm{Na}$ semana seguinte, foi elaborado nas dependências da Faculdade de Educação, Ciências e Letras de Iguatu - FECLI, um cronograma para efetivação da primeira visita e o planejamento sobre as ações que seriam desenvolvidas dentro do ambiente escolar. Como ação planejada, foi sistematizado a apresentação do projeto ao diretor escolar, a fim de contar com o interesse da escola em desenvolver na unidade escolar de ensino as ações extensivas propostas.

O primeiro contato com a escola aconteceu no dia 08 de março de 2018, onde foi apresentado pelo professor orientador do projeto Joilson Silva de Sousa, os objetivos e as ações planejadas como proposta de funcionamento dentro da escola, bem como, o público de alunos de atendimento, os horários de funcionamento, a quantidade de acadêmicos disponíveis para realização das atividades, dias da semana e os fundamentos que se espera desenvolver com os alunos do $4^{\circ}$ e $5^{\circ}$ ano do ensino fundamental.

A ideia funcional do projeto foi bem acolhida pelo diretor enquanto agente social que administra a instituição de ensino, lócus do trabalho de extensão. O mesmo enfatizou o quanto é importante à aproximação da universidade com a comunidade a sua volta, estabelecendo dessa maneira um acolhimento positivo e satisfatório do projeto. O diretor ressaltou, que a escola junto com o grupo de professores precisa de ajuda para ser trabalhada a questão da leitura e escrita com os alunos, pois são as duas áreas que mais se tornam precárias na vida escolar dos educandos de $4^{\circ}$ e $5^{\circ}$ anos da escola (público de atendimento do projeto deextensão).

\section{Primeira aula $-4^{\circ}$ ano}

A primeira ministração por parte das discentes de pedagogia que estão desenvolvendo os trabalhos do projeto foi realizada no dia 25 de Abril de 2018, em uma 
quarta-feira no horário da tarde, em sala de aula direcionada pelo coordenador pedagógico da escola. O primeiro contato com a turma do $4^{\circ}$ ano aconteceu com a presença de todos os alunos esperados 14 (quatorze) alunos divididos em 3 meninas e 11 meninos, o que nos deixou um pouco surpresas.

Tínhamos conhecimento de que os alunos estavam com dificuldades no que diz respeito à escrita e leitura, e notamos que esse obstáculo é real. Entretanto, detectamos outro infortúnio em relação a dificuldade dos alunos. Notamos que a indisciplina é um fator bem presente no cotidiano das crianças, os mesmos têm dificuldade em conversar um com o outro sem que aconteça troca de "xingamentos" não muito adequados para a faixa etária (9 e 10 anos de idade).

No primeiro momento realizamos a dinâmica da "cobra cega". Foi selecionado um aluno por meio de "zerinho ou um" (os próprios alunos que propuseram que fosse selecionado assim). O primeiro aluno teve seus olhos vendados e procuraria um de seus colegas dentro da sala, o aluno que fosse escolhido pelo colega pegaria uma das perguntas que estavam dentro de um recipiente para realizar o desafio proposto. Dessa maneira, todos os alunos participaram da dinâmica. Em um segundo momento, perguntamos se todos conheciam as letras cursivas e letras de forma, ambos falaram que conhecem a letra cursiva, só que preferem escrever com a letra de forma, por que é mais fácil de entender.

O conteúdo que abordamos na primeira aula foi sobre o conceito de "lugar". Questionamos quais os lugares eles conhecem e os nomes desses diferentes lugares. Logo, os alunos mencionaram: França, Inglaterra, Paris, Quixadá, Quixeramobim, Quixelô e por último Iguatu (município cearense onde todos residem). Em seguida, perguntamos se eles sabiam o nome do bairro em que moram, o número da casa e um ponto de referência. Poucos souberam responder, mas conhecem sua cidade e falaram que não se perderiam caso precisem voltar para casa, estando em qualquer lugar do bairro.

Questionamos as crianças acerca dos lugares de suas casas, onde dormem, a quantidade de pessoas existente em suas casas, se tem mãe e pai, se tem irmãos mais novos ou mais velhos, se moram com outras pessoas. Todos responderam às perguntas e para nossa surpresa, muitos deles moram somente com a avó e/ou irmãos, e ainda há os que moram com as tias.

A avaliação dessa aula foi realizada por meio de desenhos, onde pedimos para que todos os alunos desenhassem seu lugar preferido, muitos deles desenharam a casa dos avós, outros lugares imaginários, houve ainda desenhos de lugares que nunca foram e alguns que passaram as férias uma vez e desejam voltar. 
A primeira aula aconteceu de forma satisfatória, por mais que os alunos estivessem inquietos por estarem com pessoas diferentes em sala, teve uma troca de respeito e compreensão das atividades propostas. O único impasse existente foi que por vezes os alunos estavam querendo discutir uns com os outros.

\section{Primeira aula $-5^{\circ}$ ano}

A primeira aula do projeto para a turma do $5^{\circ}$ ano, foi realizada no dia 27 de abril de 2018, na sala da escola direcionada pelo coordenador pedagógico. O primeiro, contato que tivemos com os alunos do $5^{\circ}$ também nos deixou um pouco surpresas, dessa vez, pelo número de alunos que tivemos em sala. Os alunos que recebemos do quinto ano foram apenas 4 (quatro), os quais estavam divididos entre duas meninas e dois meninos, número bem abaixo do que esperávamos. O coordenador se desculpou pela quantidade de alunos, pois não tinha informado a turma da manhã do quinto ano que teríamos uma atividade extra no turno da tarde na escola.

No primeiro momento, realizamos a dinâmica da "cobra cega" onde o primeiro aluno teve seus olhos vendados e procuraria um de seus colegas dentro da sala, o aluno que fosse escolhido pelo colega pegaria uma das perguntas que estavam dentro de um recipiente para realizar o desafio proposto. Dessa maneira todos os alunos participaram da dinâmica, só que dessa vez, diferentemente do que ocorreu com a turma do $4^{\circ}$ ano, cada aluno realizou mais de um desafio, por conta da quantidade que tínhamos em sala.

Fizemos as mesmas perguntas, se conheciam letras de forma e a cursiva e qual das duas mais utilizavam. Ambos responderam que utilizam a letra cursiva pois "não são mais crianças para usar letra de forma”, em seguida, para conhecimento social dos alunos, perguntamos com quem eles moravam, um dos meninos respondeu que morava com a mãe e o padrasto e seus 3 (três) irmãos. O outro menino disse que morava com sua mãe, padrasto e seus 2 (dois) irmãos. Uma das meninas falou que morava com a mãe o padrasto e seus 5 (cinco) irmãos e que já tinham uma sobrinha com 2 anos e que sua avó também morava com eles. A segunda menina disse que morava com sua mãe, padrasto e seus 3 (três) irmãos.

O conteúdo que abordamos na primeira aula, bem como feito para a turma anterior, foi acerca do que eles sabem sobre o conceito de "lugar". Perguntamos que lugares eles conhecem e nomes de lugares diferentes, eles mencionaram: Alemanha, França Paris, China, Japão e por último Iguatu. Eles já souberam falar seus endereços, número da casa, ponto de referência e cor da casa que moram.

Ao final da aula de reforço escolar, a avaliação dessa aula foi por meio de desenhos, pedimos para que todos os alunos desenhassem seu lugar preferido, muitos deles desenharam 
a casa dos avós. Um dos desenhos que mais nos chamou atenção foi de uma das meninas, todos os membros de sua família estavam na praia tomando água de coco e felizes, só que no desenho apenas ela estava de sapato e todos os outros lhes faltava esse acessório, tendo em vista, um elemento inusitado considerando o lugar que a mesma expressou através da arte.

De modo geral tivemos um bom aproveitamento da primeira aula com os alunos do $5^{\circ}$ ano, a turma colaborou com as atividades propostas, chegando inclusive a se divertir com a realização da mesma.

\section{CONCLUSÃO}

Podemos concluir a escola é referência em toda a comunidade, conforme a fala do diretor, sendo a única no bairro que contempla os níveis escolar de desenvolvimento do projeto de extensão. $\mathrm{O}$ desenvolvimento do projeto supra, ocorre de acordo com os objetivos traçados em conjunto com o grupo de professores que ministram a disciplina de História e ainda com apoio da professora que coordena as atividades da sala de multimeios. Estabelecendo o planejamento do reforço escolar, tendo como ponto de partida a realidade dos alunos da escola e do grupo de professores, tornou-se possível alcançar os resultados esperados na primeira aula em que o projeto tomou forma.

O projeto de extensão desenvolvido, busca não apenas auxiliar os alunos com as atividades cotidianas do ensino regular de seus determinados anos de ensino. Mas, colaborar de modo positivo com elementos importantes para o ensino de história para os anos iniciais do ensino fundamental, onde o pedagogo, tem papel importante na consolidação das categorias de cidadania, tempo e espaço, lugar e cotidiano. E ainda, acredita-se que outros desafios serão postos em prática a partir das primeiras aproximações vivenciadas, como o respeito aooutro.

Para a coordenação escolar, o maior auxílio que o projeto de extensão "Ensino de História e Consciência Histórica no ensino fundamental I: apoio pedagógico aos alunos do Santo Antônio em Iguatu-Ce", pode potencializar na escola, trata do auxílio ao aperfeiçoamento da leitura e escrita dos alunos no $4^{\circ}$ ano do ensino fundamental, a fim de melhorar a qualidade dos alunos e os índices da escola perante a Secretaria Municipal de Educação. Desta feita, nossos esforços concentram-se também, para este desafio, buscando no ensino de história, elementos que possam contribuir com a área de déficit dos alunos supracitados. 
Vale lembrar, que o desenvolvimento de materiais pedagógicos diversificados nas aulas do reforço escolar, contribui para o aproveitamento dos educandos que estão participando das atividades extensionistas. Acreditamos construir dessa maneira, saberes disciplinares da área de ensino Ciências Humanas - História, conforme os objetivos ligados aos PCN da área, como: História Local e do Cotidiano em favor de uma educação cidadã e de identidade histórica, atribuindo ao aluno conhecer através de sua própria interpretação (motivação), trazendo a este um sentido histórico, para que seja formado nele um sujeito crítico e autônomo. 


\section{REFERÊNCIAS}

BITTENCOURT, Circe Maria Fernandes. Ensino de História: fundamentos e Métodos. São Paulo: Cortez Editora, 2011.

BOGDAN, Robert; BIKLEN, Sari Knopp. Investigação qualitativa em educação: uma introdução às teorias e aos métodos. Porto: Porto Editora,1994.

BRASIL. Constituição da República Federativa do Brasil de 1988. Brasília: Senado Federal, 1988.

2017. Ministério da Educação. Base Nacional Comum Curricular. Brasília: MEC, Secretaria da Educação Básica. Parâmetros Curriculares

Nacionais/História. Ensino Fundamental. Brasília: MEC/SEF, 1997.

CERRI, Luis Fernando. Ensino de História e Consciência histórica. Rio de Janeiro: Editora FGV, 2011.

FREITAS, Itamar. Fundamentos teóricos-metodológicos para o Ensino de História (Anos iniciais). São Cristóvão: Editora UFS, 2010.

GUIMARÃES, Selva. Didática e Prática de Ensino de História. 13.ed. São Paulo: Papirus, 2013.

HOBSBAWN, Eric. Era dos extremos: O breve século XX (1914-1991), 2.ed. São Paulo: Companhia das letras, 1995.

MINAYO, Maria Cecília de Sousa; DESLANDES, Suely Ferreira; GOMES, Romeu. Pesquisa Social: teoria, método e criatividade. 34.ed. Petrópolis: Vozes, 2015.

MOITA, Filomena Maria Gonçalves da Silva Cordeiro; ANDRADE, Fernando Cézar de. Ensinopesquisa-extensão: um exercício de indissociabilidade na pós-graduação. Revista Brasileira de Educação, v. 14, n. 41, maio/ago. 2009.

SCHIMIDT, Maria Auxiliadora; CAINELLI, Marlene. Ensinar História. São Paulo: Ed. Scipione, 2009.

THOMPSON, Edward Palmer. A miséria da teoria. Rio de Janeiro: Zahar, 1981. 